\title{
THE APPLICATION OF GIS 3D MODELING AND ANALYSIS TECHNOLOGY IN REAL ESTATE MASS APPRAISAL —— TAKING LANDSCAPE AND SUNLIGHT FACTORS AS THE EXAMPLE
}

\author{
Hui Zhang ${ }^{\text {a }}$, Yan $\mathrm{Li}^{\mathrm{a}}$, Biao Liu ${ }^{\mathrm{a}}$, Chao Liu ${ }^{\mathrm{b}}$
}

\author{
${ }^{a}$ Center for Assessment and Development of Real Estate, 518040 Shenzhen, China - Erwin_gis@ 126.com \\ ${ }^{\mathrm{b}}$ Dept. of Remote Sensing and Information Engineering, Wuhan University, 430079 Wuhan, China - \\ 643675234@qq.com
}

KEY WORDS: Procedural Modeling, 3D GIS, CityEngine, Visibility Analysis, 3D Indoor Modeling, Real Estate Mass Appraisal

\begin{abstract}
:
Based on procedural modeling approach and buildings 2D GIS data of Shenzhen, 3D external models of buildings are generated by CityEngine in a quick and batch mode. And 3D internal model is generated by vectorization of houses distribution within the target building. Following that, the landscape analysis and the sunlight analysis based on GIS visibility analysis method are applied on 3D model of the target building to get the concrete quantization indexes, such as landscape visual range and sunshine duration which could significantly influence real estate value. Finally, the drawing with 3D visualization effect for landscape information and sunshine information is produced. Compared with traditional manual modeling method, the results showed that rule-based 3D modeling method in CityEngine platform could take full advantage of existing GIS data. It could improve the efficiency of 3D modeling by rapidly and automatically generate refined building 3D models in batch mode. Meanwhile, compared with man-made subjective judgment, the building landscape and sunlight analysis model built by visibility analysis could quantify landscape and sunshine indexes more accurately. Furthermore, the application in real estate mass appraisal model for calculation and analysis will reduce the index errors caused by man-made subjective judgment. In addition, precise 3D visualization effect can provide appraisers with more intuitive and efficient view for real estate expression. It greatly improves the efficiency and accuracy in real estate appraisal.
\end{abstract}

\section{INTRODUCTION}

Based on traditional valuation method, real estate mass appraisal employs statistics, mathematics, computer and other related technologies to evaluate a large number of real estate values in one time. Compared with single-property appraisal, mass appraisal has the advantages of high efficiency and low cost (Geng, 2012). Due to powerful capabilities in spatial data analysis and display, Geographic Information Systems (GIS) technology has been widely introduced into the field of real estate mass appraisal in recent years. In this context, the traditional mass appraisal turned to GIS assisted assessment, which has the advantages of data storage, spatial analysis and visualization representation. William McCluskey proposes to apply GIS to the computer assisted mass appraisal (CAMA) to construct an integrated model of GIS and real estate assessment for property taxation purposes. The GIS data handling capacity can promote the rating and revaluation of residential properties (William, 1997). Marius Thériault presents a simulation procedure that uses GIS technology for integrating accessibility to services and working places in order to enhance property value appraisal and Hedonic modelling (Marius, 1999). David Parker use geostatistical analysis technology in GIS to carry out spatial interpolation of housing sales price to assess the real estate value ratio (David, 2011). Employment of GIS has greatly improved spatial data processing capabilities and made the construction of a more rational and efficient real estate mass appraisal model possible.

Currently, the integration of real estate mass appraisal and GIS mainly focus on the 2D GIS. However, the spatial distribution of the properties is three-dimensional, and the location information of each house is not only reflected in 2D form, but also expressed in $3 \mathrm{D}$ distribution. If appraisers only use $2 \mathrm{D}$ information, they will be unable to get the building height, visual effects, lighting, shadows and other visual factors, thus the application areas are also limited (OU, 2013). Based on 3D modeling techniques, 3D model of buildings could be generated by using the existing remote sensing image data and 2D GIS data in a quick and batch mode, this has a very important significance for 3D GIS. There are two common kinds of 3D modeling techniques: one is the using of modeling software, such as AutoCAD, 3DStudio Max, and the other is the procedural modeling by using the rules. Based on 3D modeling in AutoCAD, we can quickly generate and edit the models, accurately calculate the floor area ratio, building density, distance between buildings, but can't support texture editing, do not have the building attribute data. Based on 3D modeling in 3DStudio Max, we can create more complex 3D model, 3D scene is delicate, light and shadow rendering is realistic, support texture attached, could quickly generate a simple model, but cannot input the exact model parameters, also cannot edit and query the buildings attribute data, and only applies to the 3D reconstruction of buildings for a single building or small areas ( $\mathrm{Lu}, 2011)$. The rule-based 3D modeling method could invoke the attribute data of GIS data by rule file. It not only improves the efficiency of 3D modeling by rapidly and automatically generate refined building 3D models in batch mode, but also generate 3D internal model of buildings in batch mode, and provide a new method for the field of $3 \mathrm{D}$ rapid modeling of buildings in the big scene.

3D GIS technology has powerful three-dimensional visualization and 3D spatial analysis capability, which is an effective technical approach for the extraction of real estate spatial location information. However, due to the expertise and complexity of 3D GIS technology, it's mainly employed in urban simulation modeling and visualization representation, and 
the use of 3D GIS technology to extract the relevant information in real estate mass appraisal is still rare. In this paper, firstly using the rule-based $3 \mathrm{D}$ modeling method to carry out the simulation modeling of urban real estate in CityEngine platform in a quick and batch mode, then use the visibility analysis method that based on 3D GIS technology to get the landscape information and sunshine information which significantly influence real estate value, and make quantitative analysis and visualization representation, thus break through the limitations of getting such information traditionally relied on subjective judgment, and provide a helpful reference for information extraction of the real estate appraisal.

\section{METHODOLOGY}

\subsection{Procedural Modeling}

Procedural modeling mainly uses the CGA shape grammar to programmatically produce building models with high visual quality and geometric detail. Its core part is writing rules by analyzing the object to reuse or write rules on the basis of similarities and differences of objects. Compared with traditional manual modeling method, procedural modeling needs to write rules for different types of objects. It doesn't have many advantages at the early stage. It requires much time to write rules to generate $3 \mathrm{D}$ objects, but at the later stage it can create $3 \mathrm{D}$ objects by modifying and calling the existing rules. Since rules library is very convenient for transplanting and sharing, the efficiency of procedural modeling could have great improvement on traditional manual modelling method (Xie, 2013).

\subsection{Visibility Analysis}

Visibility analysis can be used to analyse and quantify the visual landscape of buildings and the sunshine duration of buildings during daytime. This article mainly uses the visibility analysis between two points.

The visibility analysis method of buildings usually consisted of three steps: Firstly, projecting the buildings and sight lines onto the horizontal plane by using vertical projection. Secondly, selecting the projective contour lines of buildings which intersects with the projection lines of the sight lines. Thirdly, analyzing whether the sight lines intersect with the selected buildings in 3D scene (Yin, 2011).

\section{THE CASE STUDY}

\subsection{Data Collection and Processing}

The landscape and sunshine conditions of real estate are affected not only by their own characteristics, such as location, height,but also by surrounding buildings. This article selects the JingTian district which has comparatively mature living environment and more intensive buildings in Shenzhen. This area is located in $113^{0} 46^{\prime} \sim 114^{0} 37^{\prime} \mathrm{E}$ and $22^{0} 27^{\prime} \sim 22^{0} 52^{\prime} \mathrm{N}$, and the buildings in this area are mainly high-rise residential buildings. The terrain data uses DEM of FuTian district with 1:10000 scale and 3.28 meters resolution, and the building footprints data adopt buildings base projection distribution map, along with attribute information such as building height, the number of floors and floor height, and the texture data are got mainly by digital camera shooting the peripheral surface of buildings. To analyze the landscape and sunshine conditions of each house, by vectorization of rooms distribution within the target building, this article got room distribution data of each floor. Towards original building footprints data, before used for 3D modeling, we need to preprocess them, and combine with the terrain data to create the $3 \mathrm{D}$ polygonal features which attached to the surface of the terrain.

\subsection{Building 3D Modeling Using ESRI's CityEngine}

$3 \mathrm{D}$ modeling procedure mainly includes two steps, first step is generating $3 \mathrm{D}$ external models of buildings in a quick and batch mode, second step is generating 3D internal model of the target building.

This article uses ESRI's CityEngine software for 3D modeling of buildings which can quickly generate 3D models using existing 2D GIS data. CityEngine relies on three key topics: feature geometry, feature attributes, and procedurally defined rules. The more detail provided in each of these elements, the greater the complexity and real-world accuracy that will be included in the generated 3D content. Firstly, the building footprints are extruded to 3D structures by height attribute. Then, according to attribute fields such as the number of floors, floor height, window location, the buildings are built by rules. Finally, the 3D external models of buildings are produced.

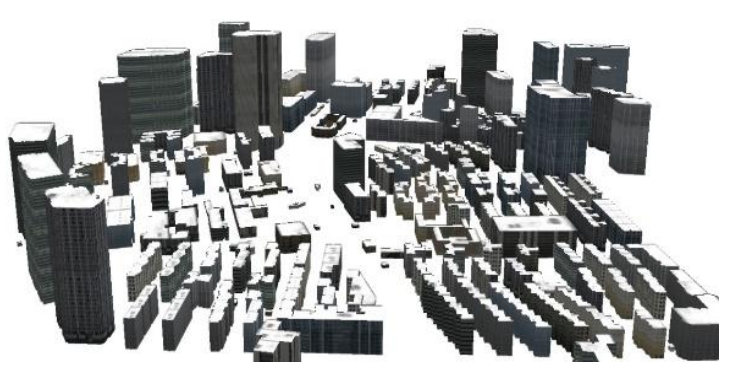

Figure 1. 3D Building Models

Meanwhile, by using house distribution data of each floor in the target building and the rule file of CityEngine, firstly we identify each floor, then we extrude them according to corresponding floor height of each floor, stack them on the top, and separately add texture to each floor. Thus, the 3D internal models of buildings are generated in a batch mode by rulesdriven.

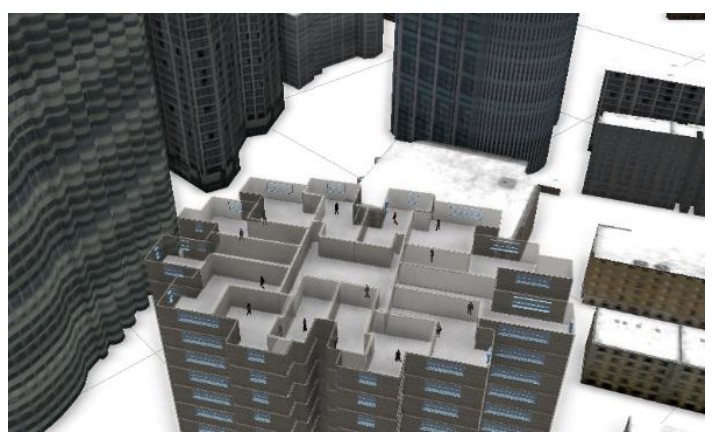

Figure 2. 3D Internal Model of the Target Building

\subsection{Landscape Analysis}

The landscape analysis takes the building as an observer, and takes the landscape wall which represent Hill as a target. Firstly, CityEngine is used to sample the building and the landscape wall to create regular sampling points and corresponding 
rectangular panels which represent the windows of houses. Secondly, 3D analysis tools and ModelBuilder of ArcGIS are used to create 3D analysis workflow which carry out visibility analysis on sampling points between the building and the landscape wall, and select the sightlines which represent intervisibility between the building and the landscape wall. Thirdly, the number of target points on the Hill landscape that can be seen by each observation point on the building could be obtained. This number could be regarded as a quantization index which represent the landscape visual range. The larger the number, the better the intervisibility.

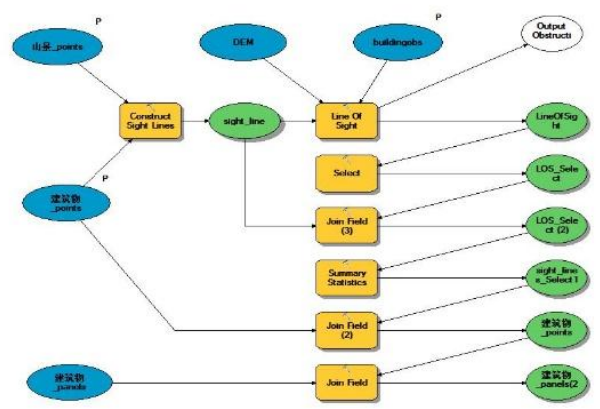

Figure 3. the GP Model of Landscape Analysis Created by ModelBuilder(Take Hill View as an Example)

The statistical results of landscape analysis of the observer building are shown in Table 1(take 13th Floor as an example):

\begin{tabular}{ccc}
\hline House Number & $\begin{array}{c}\text { House } \\
\text { Orientation }\end{array}$ & $\begin{array}{c}\text { Landscape } \\
\text { Visual Range }\end{array}$ \\
\hline A-1301 & South & 6 \\
A-1302 & South & 5 \\
A-1303 & South & 6 \\
B-1304 & North & 6 \\
B-1305 & South & 8 \\
B-1306 & East & 25 \\
B-1307 & East & 11 \\
\hline
\end{tabular}

Table 1. the Statistical Results of Building Landscape Analysis

The 3D visualization effect drawing shown in Figure 5 is got by classification rendering of rectangular panels of the building according to the landscape visual range of the corresponding points, and the gradient colours from green to red represent the landscape range from small to large.

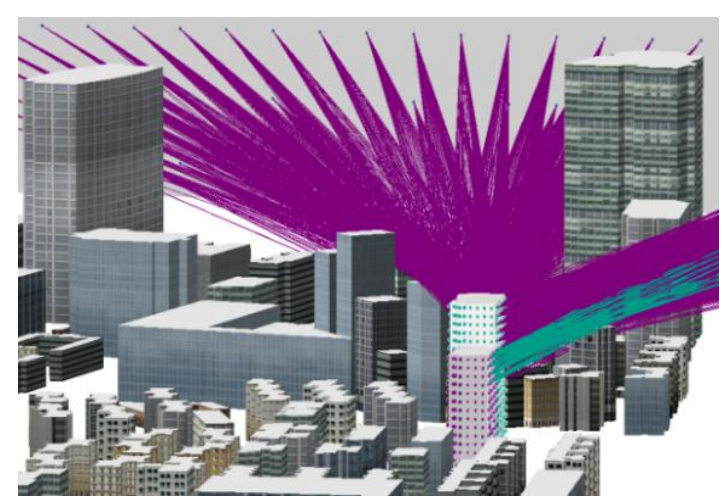

Figure 4. Schematic Diagram of Landscape Analysis

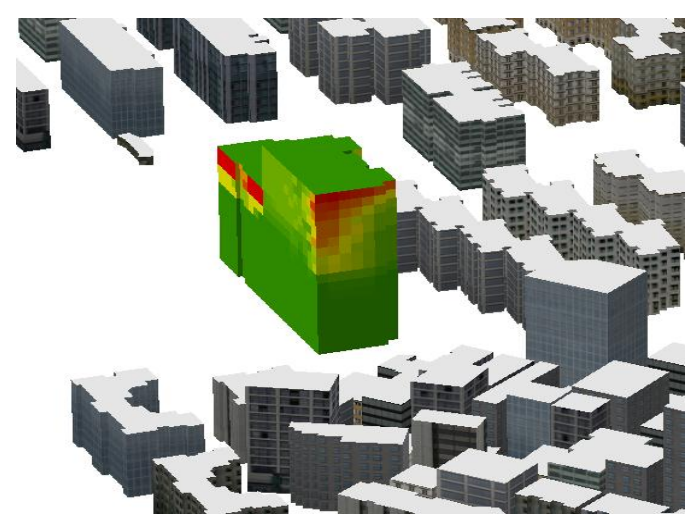

Figure 5. Visualization Effect Chart of Landscape Analysis

The results shown in Figure 6 is got by rendering several main houses selected from the target building according to the landscape range:

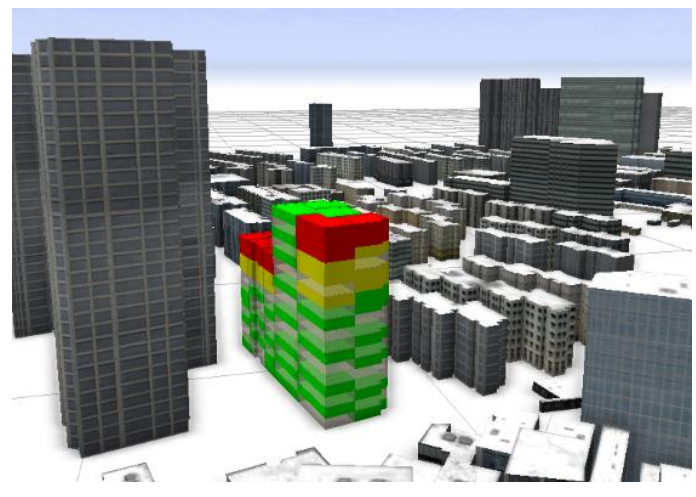

Figure 6. Rendered Chart of Landscape Analysis

\subsection{Sunlight Analysis}

Sunlight Analysis also adopts visibility analysis method similar to the one used in landscape analysis, by writing Python script program can generate multiple sun points model of certain period of time, and the difference here is taking sun points as the target.

The sunlight analysis firstly uses CityEngine to create regular sampling points and corresponding rectangular panels, and then uses 3D analysis tools to carry out visibility analysis between sampling points of the building and the sun points. Each observation point on the building will be assigned a value to indicate the visibility between the observation point and the sun. 
The statistical results of sunlight analysis are shown in Table 2(take 25th Floor as an example), and the simulated time period is from 7:00 to 18:00:

\begin{tabular}{cccc}
\hline House Number & $\begin{array}{c}\text { House } \\
\text { Orientation }\end{array}$ & $\begin{array}{c}\text { Lighting } \\
\text { Time }\end{array}$ & $\begin{array}{c}\text { Sunshine } \\
\text { Duration }\end{array}$ \\
\hline $25 \mathrm{~A}$ & South & 10 & $7: 00-$ \\
& & & $9: 00,11: 00-$ \\
$17: 00$ \\
& & & $13: 00-18: 00$ \\
$25 \mathrm{~B}$ & Southwest & 6 & $13: 00-$ \\
$25 \mathrm{D}$ & West & 5 & $15: 00,17: 00-$ \\
& & & $18: 00$ \\
& & 6 & $13: 00-18: 00$ \\
$25 \mathrm{~F}$ & Northwest & 6 & $9: 00-12: 00$ \\
$25 \mathrm{G}$ & North & 0 & $7: 00-$ \\
$25 \mathrm{I}$ & Northeast & 4 & $8: 00,10: 00-$ \\
$25 \mathrm{~K}$ & East & 5 & $12: 00$ \\
& & & $7: 00-18: 00$ \\
& & 10 & \\
$25 \mathrm{M}$ & Southeast & 12 & \\
$25 \mathrm{~N}$ & South & $12: 00$ \\
\hline
\end{tabular}

Table 2. the Statistical Results of Building Sunlight Analysis

The above statistical results indicate that, the house facing south whose time of accepting the sun exposure is the longest during the day; and the house facing east and the house facing west is basically the same, but the house facing east accepting the sun exposure is mainly on the morning, and the house facing west is focus on the afternoon; moreover the house facing north is the shortest during the day.

By counting the visibility conditions between the houses of four orientations and the sun in the simulated time period from 7:00 to 18:00, we get the graphs shown in Figure 7, and 1 represents visible, 0 represents invisible.

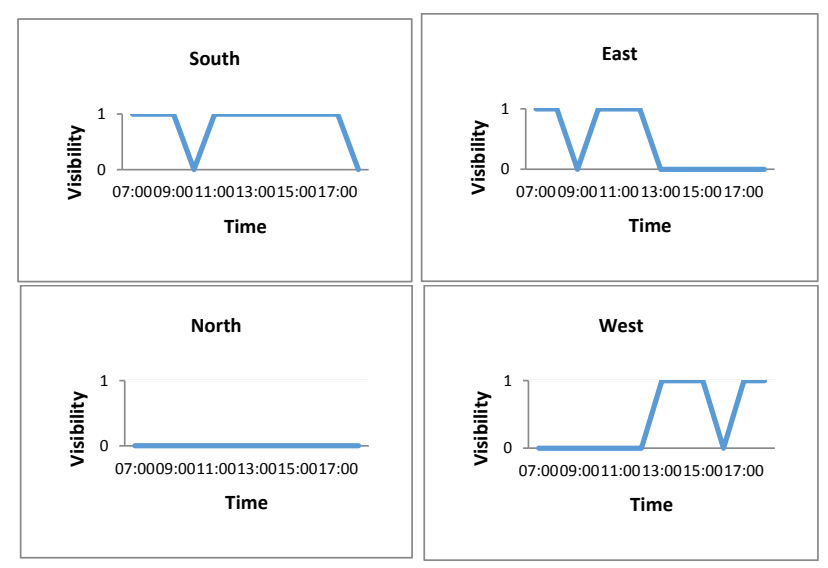

Figure 7. Visibility Graphs Between the Houses of Different Towards And the Sun

From the above statistical results, we can get the specific time range of the houses of different towards accepting the sun exposure during the day, this can help to avoid the limitation brought by only using the lighting time to measure the lighting quality of houses, meanwhile for the housing type which has the inner room or sitting room whose lighting surface facing west, to determine whether its "western exposure" problem in the afternoon is in the acceptable range.

The 3D visualization effect chart shown in Figure 9 is got by classification rendering corresponding rectangular panels of the building according to the lighting time, and the graduated colour from red to green represent the sunshine duration in a day from long to short:

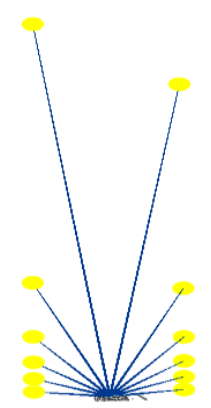

Figure 8. Sun Points Model

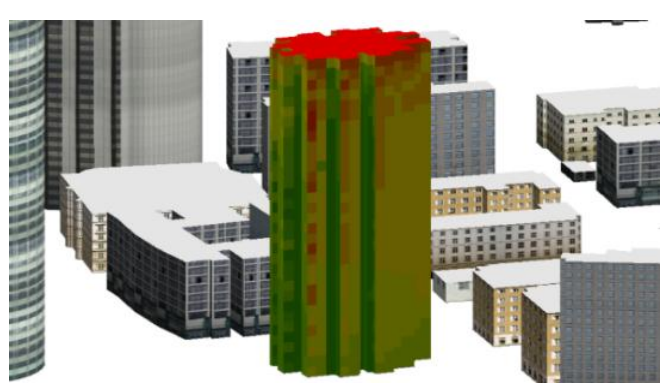

Figure 9. Visualization Effect Chart of Sunlight Analysis

The results shown in Figure 10 are got by rendering several main houses selected from the target building according to the lighting time:

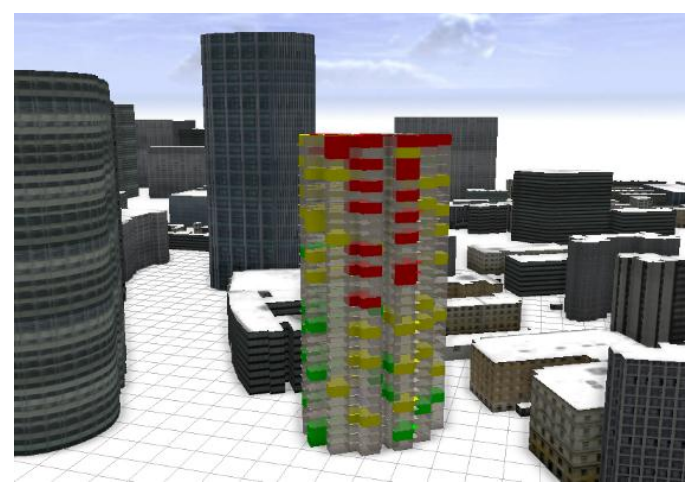

Figure 10. Rendered Chart of Sunlight Analysis

\subsection{Summary}


By comparing the concrete quantization indexes of landscape factor and sunshine factor got by the analysis with the subjective evaluation grade, the results are shown in Table 3 and Table 4:

\begin{tabular}{cccc}
\hline House Number & $\begin{array}{c}\text { House } \\
\text { Orientation }\end{array}$ & $\begin{array}{c}\text { Subjective } \\
\text { Evaluation } \\
\text { Level }\end{array}$ & $\begin{array}{c}\text { Quantization } \\
\text { Value of } \\
\text { Landscape }\end{array}$ \\
\hline A-1301 & South & Moderate & 6 \\
A-1302 & South & Moderate & 5 \\
A-1303 & South & Moderate & 6 \\
B-1304 & North & Moderate & 6 \\
B-1305 & South & Moderate & 8 \\
B-1306 & East & Best & 25 \\
B-0906 & East & Best & 7 \\
B-1307 & East & Good & 11 \\
B-0907 & East & Good & 5 \\
\hline
\end{tabular}

Table 3. Correlation Table of Landscape Analysis

\begin{tabular}{cccc}
\hline House Number & $\begin{array}{c}\text { House } \\
\text { Orientation }\end{array}$ & $\begin{array}{c}\text { Subjective } \\
\text { Evaluation } \\
\text { Level }\end{array}$ & $\begin{array}{c}\text { Quantization } \\
\text { Value of } \\
\text { Sunlight }\end{array}$ \\
\hline $25 \mathrm{~A}$ & South & Best & 10 \\
$25 \mathrm{~B}$ & Southwest & Good & 6 \\
$25 \mathrm{D}$ & West & Good & 5 \\
$25 \mathrm{~F}$ & Northwest & Good & 6 \\
$25 \mathrm{G}$ & North & Worst & 0 \\
$25 \mathrm{I}$ & Northeast & Moderate & 4 \\
$25 \mathrm{~K}$ & East & Good & 5 \\
$25 \mathrm{M}$ & Southeast & Best & 10 \\
$25 \mathrm{~N}$ & South & Best & 12 \\
\hline
\end{tabular}

Table 4. Correlation Table of Sunlight Analysis

The comparison results indicate that the analysis in this paper could quantify landscape and sunshine indexes more accurately than man-made subjective judgment, take House $25 \mathrm{~A}$ and $25 \mathrm{~N}$ as an example, though the sunlight level of the two houses are classified as Best, yet there's a difference between their lighting time; and the analysis can also correct the mistakes caused by subjective judgment, take House B-0906 and B-1306 as an example, though the landscape level of the two houses by manmade judgment are Best, but because of the block of the buildings, in fact the landscape range of House B-0906 is smaller than B-1306, so should classify the sunlight level of House B-0906 as Moderate, and this will be more reasonable. In conclusion, compared with subjective judgment, based on the spatial analysis method of 3D GIS, we can get the concrete quantization indexes of landscape factor and sunshine factor from a large amount of real estate spatial data in a quick and batch mode, that reduce the costs; Meanwhile, the refined quantitative values obtained can directly apply to real estate mass appraisal model for calculation and analysis, this help to reduce the index errors brought by man-made subjective judgment; In addition, precise 3D visualization effect can provide appraisers with more intuitive and efficient view for real estate expression, and this help appraiser to make more accurate judgment in the real estate appraisal.

\section{CONCLUSIONS}

Compared with 2D GIS, 3D GIS decibels the objective world in a more realistic way, which shows geospatial phenomena to users by $3 \mathrm{D}$ modeling technology. It not only expresses the relationships between spatial objects in the plane but also describes and expresses the vertical relationship between them. In addition, carrying out 3D spatial analysis for spatial objects is the unique functions of 3D GIS (Tan, 2003). With the development and application of computer hardware and software as well as 3D GIS technology, if integrate the real estate mass appraisal model with 3D GIS, on the one hand make full use of 3D GIS spatial data management capabilities, 3D spatial visualization skills and 3D spatial analysis capabilities, in the other using the assessment model for the real estate mass appraisal, that will undoubtedly have a strong advantage. Firstly, this paper use 3D modeling technology to generate refined 3D model of the buildings, and then through carrying out the landscape analysis and sunshine analysis for a large number of real estate data, extract the quantitative information which have a significant impact on the real estate price, such as landscape visibility and lighting length. Compared to the previous valuation results, it's more convenient for appraisers to make the right judgments and could greatly improves the efficiency and accuracy of the valuation.

\section{REFERENCES}

David. P., Tony. L., Wayne. M., 2011. Mass Appraisal Certification Standards - The Spatial Dimension. 17th Pacific Rim Real Estate Society Conference.

Geng. J.J., Zhang. H., 2012. Research on Real Estate Mass Appraisal Database Construction based on GIS:Taking Shenzhen as an Example. Remote Sensing Technology and Application 27 (3), 479-486.

Lu. Ch.Y., Wei. H.Y., Li. J.Y., 2011. IMAGIS application in city three-dimensional modeling. Science of Surveying and Mapping 36 (6), 270-272.

Marius. T., Fiancois. D.R., Marie. H.V., 1999. GIS-based Simulation of Accessibility to Enhance Hedonic Modeling and Property Value Appraisal. IAAO.

OU. W.S., 2013. Construction Technical Applied Research Based on 3D Visualization of Construction Projects Planning Reported. Beijing Surveying and Mapping 2, 37-40.

Tan. R.Ch., Jiang. W.P., Du. Q.Y., 2003. Data acquirement and modeling of the building in 3D GIS. Engineering of Surveying and Mapping 12 (1), 20-23.

William. M., William. D.,Adam. M., Dillon. M., Richard. B., 1997. Interactive application of computer assisted mass appraisal and geographic information systems. Journal of Property Valuation and Investment 15 (5), 448 - 465.

Xie. N., Xiang. Y., Xu. T.W., 2013. Research on Rapid 3D Modeling Technology Based on Rules. Urban Geotechnical Investigation \& Surveying 4, 5-8.

Yin. Ch.L., Xu. W.Q., 2011. Visibility analysis model of urban planning based on 3DGIS. Science of Surveying and Mapping 36 (4), 142-144. 